\title{
Uso de diodos emissores de luz (LED) de potência em laboratório de Óptica ${ }^{+*}$
}

\author{
L. C. S. Pinheiro \\ C. E. da Silva \\ A. M. Freitas \\ A. J. Santiago \\ Instituto de Física - UERJ \\ Rio de Janeiro - RJ
}

\section{Resumo}

Após iluminar casas, edificios e ruas há mais de 100 anos, a lâmpada incandescente criada por T. A. Edison, em breve se tornará uma relíquia do passado. Muitos países têm tomado medidas para substituí-la por outra fonte de energia luminosa mais eficiente. Adicionalmente, as lâmpadas incandescentes têm sido gradativamente substituidas pelas lâmpadas fluorescentes que são mais econômicas e, atualmente, em iluminação residencial, pelas suas equivalentes compactas. Porém, este tipo de lâmpada está começando a ser substituida e a alternativa que se apresenta são os LEDs de potência. Nos laboratórios de ensino de óptica é comum a utilização de vários tipos de fontes de luz, desde uma simples vela até os lasers semicondutores. Assim, em experimentos que envolvem óptica geométrica e polarização da luz, entre outros, é comum o uso de fontes tradicionais, como por exemplo, as fontes incandescentes e as fontes a gás de baixa pressão. Já nos experimentos que envolvem os fenômenos de interferência da luz, facilita bastante usar fontes de elevado grau de coerência, tais como lasers a gás

\footnotetext{
Use of the power Led in Optics laboratories

* Recebido: fevereiro de 2013.

Aceito: novembro de 2013.
} 
e lasers semicondutores. A proposta deste trabalho é apresentar, de maneira simples e didática uma fonte de luz e sua respectiva fonte de alimentação, que utiliza como componente principal um LED de potência e mostrar que esta pode substituir com muitas vantagens as fontes de luz tradicionalmente empregadas em muitos experimentos de óptica.

Palavras-chave: Ensino de óptica. LED de potência. Luz branca. Luz fria.

\begin{abstract}
After lighting homes, streets and buildings for over 100 years, the incandescent bulb created by T. A. Edison, will soon become a relic of the past. Many countries have taken steps to replace it to another more efficient light energy source. Additionally, the incandescent bulbs have been gradually replaced by fluorescent bulbs that are more economical and, currently, in residential lighting, their compact equivalents. However, this type of lamp is beginning to be replaced and the alternative that presents itself is the power LED. In Optics laboratories teaching is common to use several types of light sources, from a simple candle to semiconductor lasers. Thus, in experiments involving Geometric Optics and light polarization, among others, it is common to use traditional sources such as incandescence and low pressure gas. In experiments involving the phenomenon of light interference, it is easier to use sources of high grade of coherency, such as gas lasers and semiconductor lasers. The purpose of this paper is to present, in a simple and didactic way, a source of light that uses a LED power and show that it can replace, with many advantages, the light sources traditionally used in many optical experiments.
\end{abstract}

Keywords: Teaching Optics. Power LED. White light. Cold light.

\title{
I. Objetivo
}

A proposta deste trabalho é apresentar uma alternativa simples, eficiente, acessível e de baixo custo ao emprego de fontes convencionais de luz utilizadas em 
laboratórios de ensino de óptica, substituindo-as por LED (Light Emitting Diode $L E D$ ) de potência. O principal objetivo é substituir as lâmpadas incandescentes dos antigos bancos ópticos por LEDs de potência aproveitando a montagem original. Esses LEDs são facilmente encontrados no mercado especializado e seu preço, com a massificação, é cada vez mais atraente, competindo assim, em muitos casos, com as fontes incandescentes, as lâmpadas a gás e os pequenos lasers semicondutores.

Desta forma, com algumas modificações, como por exemplo, a substituição da lâmpada incandescente existente nos bancos ópticos tradicionais por um LED ou, construindo uma nova fonte óptica, é possível ter uma fonte de luz branca, de elevada intensidade (depende da potência do LED), com pequenas dimensões, baixo peso, pouco aquecimento, grande durabilidade, baixo custo relativo, emprego de baixa tensão, etc.

No entanto, para realizar a substituição da lâmpada convencional por um LED de potência, é necessário o uso de uma fonte de alimentação apropriada que deve fornecer corrente constante para o LED. Ela pode ser adquirida pronta no comércio especializado ou construída sem dificuldades.

\section{Introdução}

A iluminação elétrica teve seu início no século XVIII quando pesquisas evidenciaram o uso da energia elétrica para a geração de luz, através de descarga elétrica em uma ampola rarefeita de quartzo - Ampola de Crookes.

Mas foi no século XIX que diversos inventores tentaram construir fontes de luz utilizando energia elétrica. Em 1802, H. Davy, construiu a primeira fonte de luz com um filamento de platina. Nesta fonte o filamento aquecia-se pela passagem da corrente elétrica a ponto de emitir luz visível. Décadas depois, T. A. Edison, construiu a primeira lâmpada incandescente comercializável. Esta lâmpada emitia luz através do aquecimento de um filamento de carbono que posteriormente foi substituído por um filamento de tungstênio, permitindo maior potência luminosa e grande durabilidade. Para evitar a combustão do filamento, que queimavam rapidamente, removeu-se todo o ar da lâmpada, enchendo-a com a mistura de gases inertes como o nitrogênio e argônio ou criptônio ${ }^{[1]}$.

Apesar de todas as melhorias feitas nas lâmpadas incandescentes desde a sua invenção, no processo de transformação da energia elétrica em energia luminosa, ela ainda produz grande quantidade de energia térmica. Assim, com o intuito de se conseguir uma lâmpada que apresente rendimento superior às lâmpadas incandescentes foi desenvolvida a lâmpada fluorescente. 
A lâmpada fluorescente é classificada como uma lâmpada de descarga de baixa pressão. Assim, a luz é produzida pela passagem da corrente elétrica através do gás contido em um tubo (ou uma mistura de gases). Quando a diferença de potencial aplicada aos eletrodos da lâmpada supera a rigidez dielétrica do meio gasoso, ocorre a ignição da lâmpada.

Quando comparadas às lâmpadas incandescentes, as fluorescentes apresentam algumas vantagens, tais como: maior vida útil, maior eficiência luminosa (produzem menos calor), elevada temperatura de cor (luz branca), etc. Por outro lado, no entanto, elas apresentam algumas desvantagens, como por exemplo, em sua composição, utilizam gases nocivos aos seres humanos e ao meio ambiente, necessitam de um reator externo para o seu acionamento, elevando assim o seu custo, possui grande comprimento, o que dificulta o seu uso como fonte de luz em laboratório de ensino de óptica, etc. Para solucionar esses problemas, foram criadas as lâmpadas fluorescentes compactas, que apesar das suas dimensões reduzidas, já vem com o reator embutido no soquete da lâmpada. Apesar dos resultados satisfatórios produzidos por essas lâmpadas, no entanto, uma nova alternativa está se mostrando muito viável na substituição delas e pode melhorar ainda mais os resultados apresentados por essas fontes, os $\operatorname{LEDs}^{[1-2]}$.

LEDs são dispositivos semicondutores que surgiram na década de 1960 e seu princípio de funcionamento está baseado na eletroluminescência, emitindo luz através da combinação de elétrons e lacunas. Operam na faixa do visível, infravermelho e ultravioleta. Inicialmente eles eram utilizados em iluminação indicativa, mas com o desenvolvimento de LEDs mais potentes e com maior luminosidade foi possível utilizá-los em uma ampla faixa de aplicações ${ }^{[3]}$.

O uso de LED de potência apresenta muitas vantagens quando comparados com as lâmpadas convencionais, por exemplo, alto brilho e intensidade, elevada eficiência, baixa tensão de operação (permitindo o uso de baterias, coletores solares, dínamos, etc.), acendimento instantâneo, imunidade às vibrações (grande robustez física), elevada vida útil ( $\sim 0.000$ horas), sua intensidade luminosa pode ser facilmente controlada (dimerização), são compactos e de fácil controle óptico (existem várias opções de lentes externas que podem ser acopladas ao LED), etc. Como desvantagens, podemos citar o custo elevado (com a massificação a tendência é baixar), necessidade de controle térmico e necessidade de maior conhecimento técnico para sua aplicação. Por conseguinte, o LED passou a ser um componente de grande interesse em situações em que não é necessária coerência elevada ${ }^{[2,4]}$.

Os LEDs de potência mais comuns são os de 1,3 e 5 watts ${ }^{[5]}$. No entanto, existem LEDs cuja potência pode chegar aos 50 watts $^{[4]}$. Desta forma, a substitui- 
ção das fontes ópticas de baixa coerência tradicionais em laboratório de ensino de óptica, por LED de potência é justificada.

Os LEDs podem ser classificados em três categorias distintas: indicativos, de alto brilho e de potência. Os LEDs indicativos são aqueles utilizados somente para iluminação indicativa em painéis de equipamentos elétricos e eletrônicos, indicando se estes estão em funcionamento ou não. Os LEDs de alto brilho são encapsulados em resina epóxi, transparente, com uma lente concentradora integrada em seu corpo. São utilizados em semáforos, sistemas de iluminação de emergência, etc. Esses dois tipos de LEDs operam com correntes de 20 a $70 \mathrm{~mA}$ e com potências que variam de 0,05 a 0,2 watt. Já os LEDs de potência (ou de alto fluxo) permitem a utilização em iluminação de ambientes, dentre outras aplicações. São encapsulados em um invólucro especial, com base metálica, para permitir a fácil transferência de calor do LED para o dissipador externo. Nas Fig. 1, 2 e 3, ilustram-se os três tipos de LEDs citados ${ }^{[2,5-6]}$.

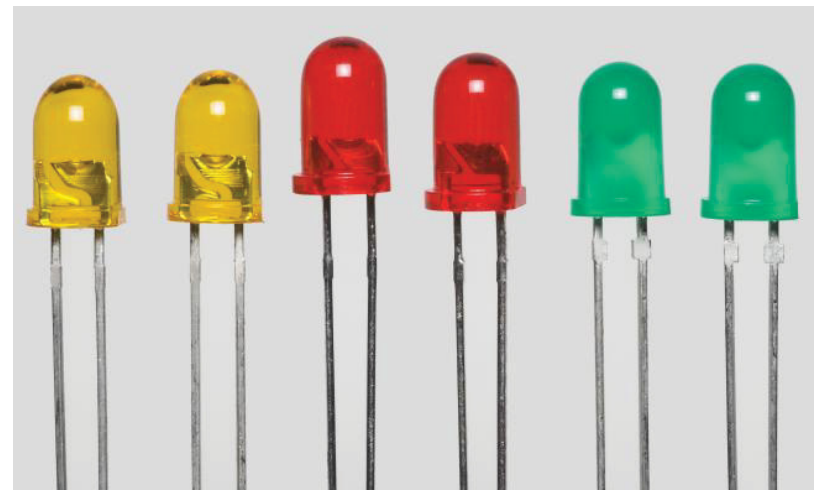

Fig. 1 - LEDs indicativos.

\section{Fonte de alimentação para o LED de potência}

Para o funcionamento adequado do LED de potência é necessário um circuito eletrônico capaz de fornecer tensão e corrente apropriada. Deseja-se também, que este seja compacto, eficiente, que possua baixo custo e que possa ser ligado diretamente à rede elétrica. Este circuito existe e pode ser facilmente encontrado 


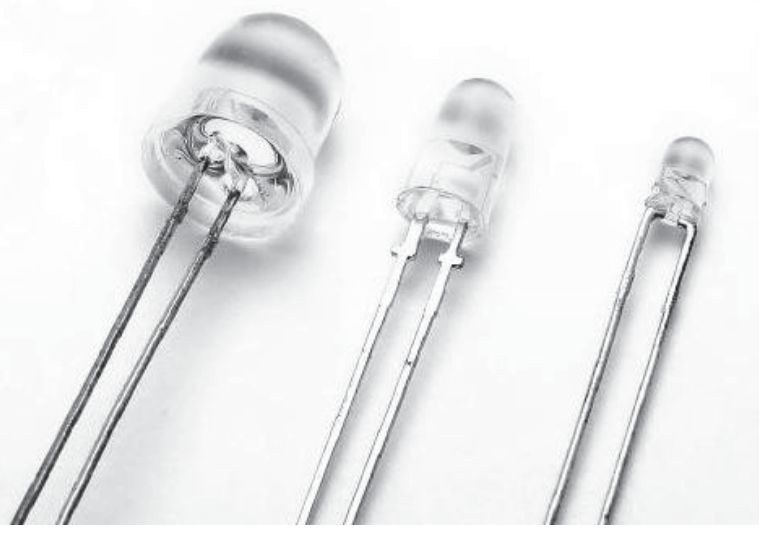

Fig. 2 - LEDs de alto brilho.
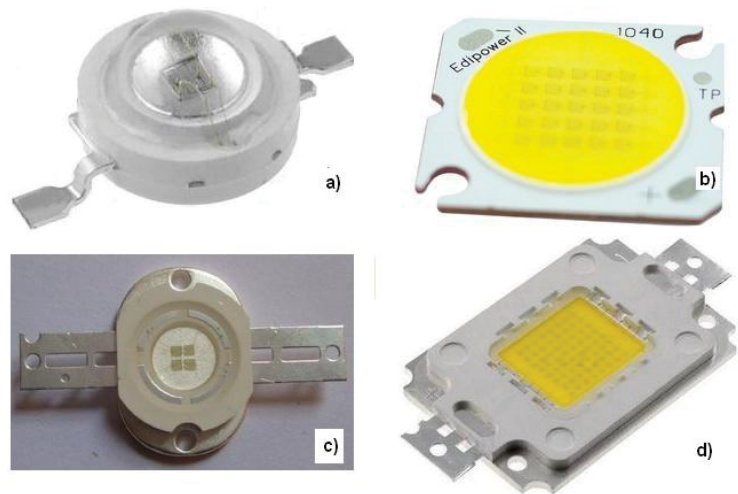

Fig. 3 - Tipos de LEDs de potência disponiveis no mercado especializado: a) LED branco (1 ou 3 watts). b) LED branco (4, 6, 8 ou 15 watts). c) LED branco 10 watts. d) LED branco 30 ou 50 watts.

pronto no mercado especializado ${ }^{[7]}$. Circuitos para essa finalidade são comumente chamados de "drivers" para LED e são, na verdade, fontes de corrente contínua constante projetados para alimentar o LED de potência. Essas fontes encontram-se disponíveis com correntes de saída de 300, 350, 500, 600, 700, 1000 e $1200 \mathrm{~mA}$, atendendo a quase todas as linhas de LEDs de potência. Apesar do tamanho compacto, essas fontes possuem alta eficiência, ampla faixa de tensão de entrada, pos- 
suem proteção contra sobreaquecimento e, alguns modelos, podem variar a intensidade da corrente na saída (dimerização) ${ }^{[2]}$.

Como foi dito antes, as fontes para LEDs podem ser encontradas prontas no mercado e não necessitam de componentes adicionais. A ligação do LED à fonte é extremamente fácil e é feita diretamente aos seus terminais. O único cuidado a se tomar é com a polaridade do LED. Além disso, essas podem ser ligadas diretamente à rede de $100 \mathrm{~V}_{\mathrm{AC}}$ a $240 \mathrm{~V}_{\mathrm{AC}}$.

Para a montagem proposta neste trabalho, foram adquiridas fontes com potência de 6 watts. Na Fig. 4, a seguir, tem-se a fonte comercial de corrente constante conectada ao LED de potência, utilizados nesta montagem ${ }^{[7-8]}$.

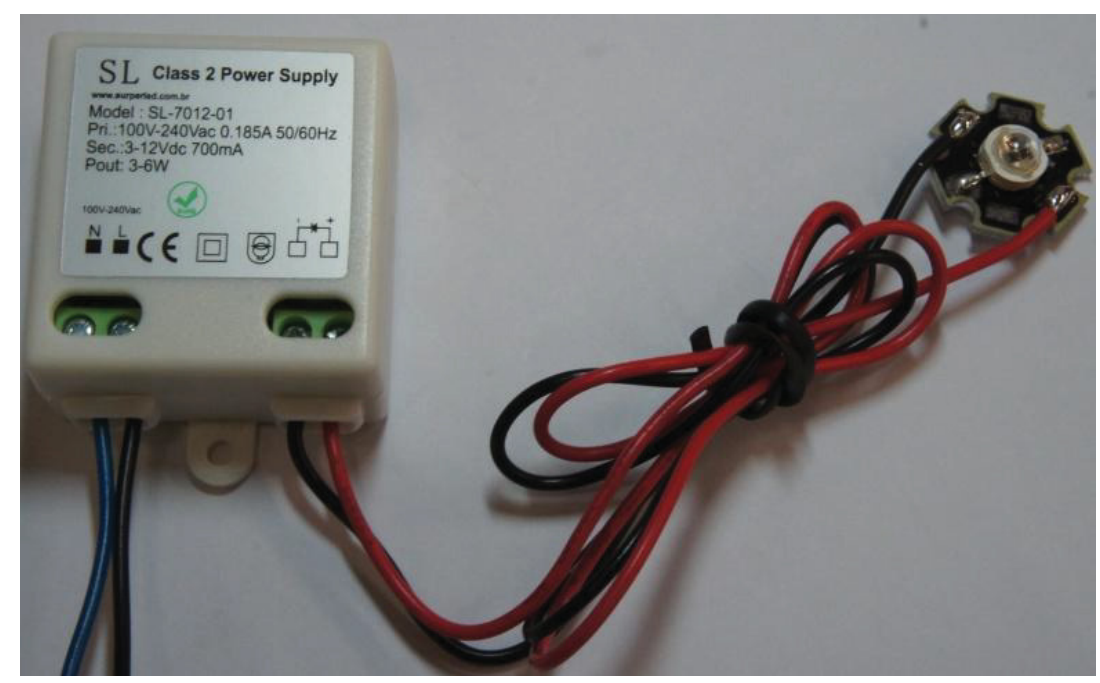

Fig. 4 - Fonte comercial de 6 watts com LED de potência.

\section{III.1 A escolha do LED de potência}

O LED de potência é o elemento mais importante desse trabalho, pois é ele que substituirá a lâmpada incandescente presente nos kits ópticos disponíveis em muitos laboratórios de óptica.

Dentre as alternativas de LEDs de potência disponíveis no mercado, o escolhido é semelhante àquele mostrado na Fig. 3a e suas principais características são mostradas na Tabela 1, a seguir. 
Tabela 1. Principais características do LED de potência escolhido ${ }^{[4]}$.

\begin{tabular}{|l|c|}
\hline Cor da iluminação & $\begin{array}{c}\text { Branco Frio (6000 K a 7000 K) } \\
\text { (Não polarizada) }\end{array}$ \\
\hline Lente & Lente transparente \\
\hline Ângulo de iluminação & $120^{\circ}$ \\
\hline Tensão de trabalho & $3,2 \mathrm{~V}$ a 3,6 V \\
\hline Corrente máxima & $700 \mathrm{~mA}$ \\
\hline Potência & $3 \mathrm{~W}$ \\
\hline Potência de iluminação & 180 a 200 Lumens \\
\hline Dimensões & $20 \mathrm{~mm} \times 6,6 \mathrm{~mm}$ \\
\hline
\end{tabular}

Devido à relativa potência elevada, o LED deve ser montado sobre uma estrutura metálica de forma a dissipar o calor gerado. No comércio eletrônico é possível encontrar suportes de alumínio, chamados "estrelas", que são utilizados para a fixação mecânica e conexões elétricas do LED. Contudo, além da estrela, é necessário o uso de um pequeno dissipador de calor, que no nosso caso foi utilizado um pequeno disco de cobre, um pouco maior do que a estrela de alumínio.

De posse desses materiais, solda-se o LED à estrela e prende-se está ao dissipador de calor. Na montagem utilizamos dois pequenos parafusos com porca para fixar a estrela ao disco metálico.

A Fig. 5 mostra o LED utilizado montado sobre a estrela de alumínio.

\section{III.2 Conjunto óptico com lâmpada incandescente}

A fonte de luz original foi fabricada pela Leybold Optics. Ela é constituída de uma pequena lâmpada incandescente de 12 volts e 21 watts que fica alojada no interior da montagem que é, basicamente, constituída de dois tubos concêntricos. Esse conjunto ainda dispõe de três parafusos e uma mola central que permitem alinhar a lâmpada com o eixo de simetria do da montagem. As Fig. 6 e 7 permitem um melhor entendimento desses detalhes. 


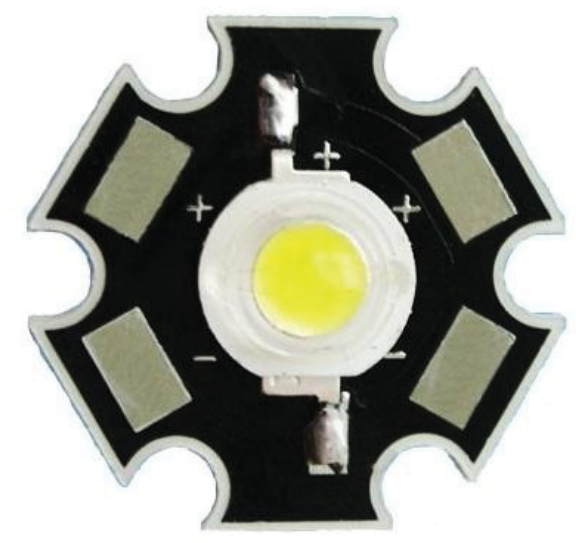

Fig. 5 - LED de potência montado sobre a estrela de alumínio.

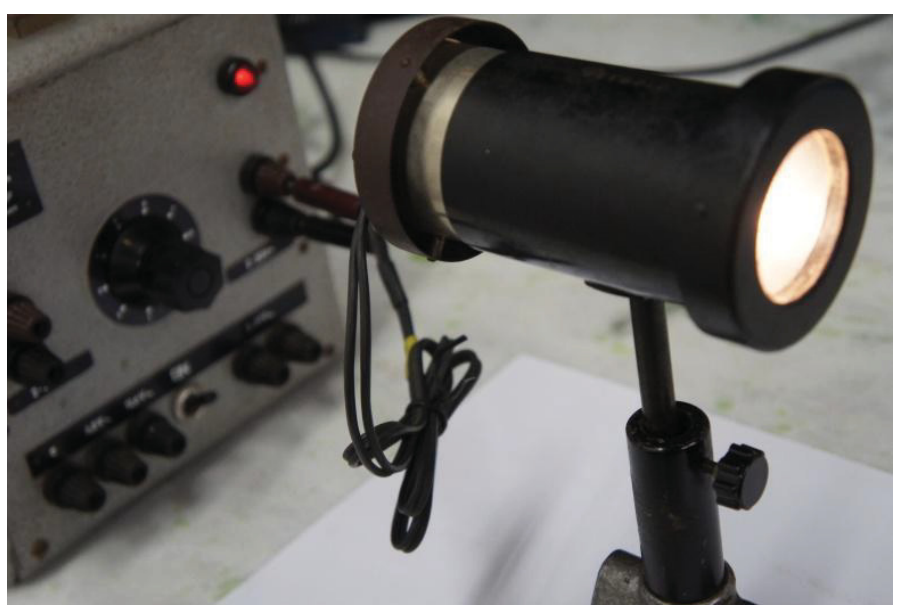

Fig. 6-Fonte óptica da Leybold Optics utilizando lâmpada incandescente.

\section{III.3 Montagem do conjunto óptico com LED de potência}

Em cada unidade de fonte de luz foi utilizado um LED de 3 watts. Esse LED foi montado inicialmente sobre uma estrela de alumínio que está presa, por sua vez, a um dissipador de calor. 
A modificação da fonte original (fonte óptica da Leybold Optics) se baseia na substituição da lâmpada incandescente pelo LED de potência e a colocação da fonte de corrente constante dentro do conjunto. O LED está montado sobre um sistema mecânico, constituído de dois discos metálicos, três parafusos de regulagem, duas hastes metálicas e uma mola central. Esse arranjo permite alinhar o feixe de luz com o eixo do conjunto. As hastes metálicas separam o disco sobre o qual está montado o LED do sistema de alinhamento. Essa separação é suficiente para colocar a fonte de corrente constante dentro da montagem. A montagem mecânica original foi mantida. A Fig. 7 mostra o esquema do conjunto modificado.
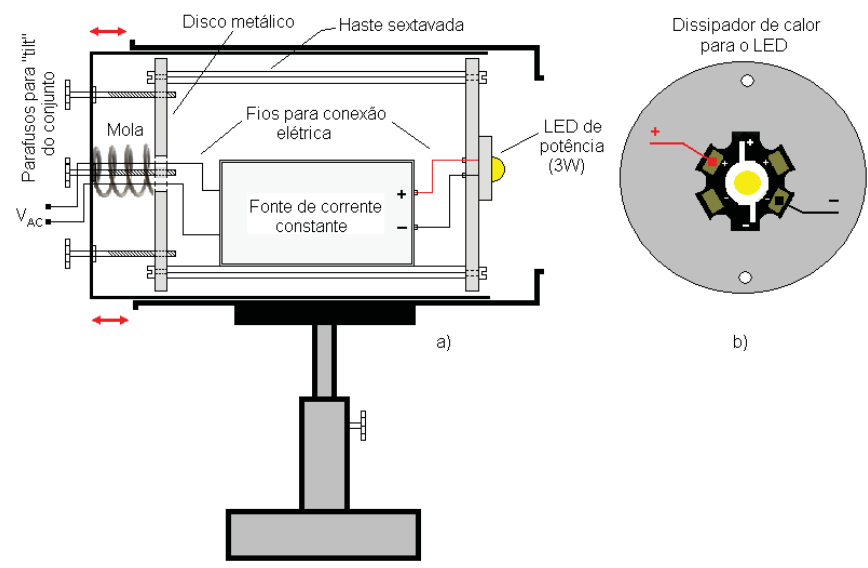

Fig. 7 - Esquema da montagem do LED de potência utilizando fonte comercial. a) Esquema do conjunto da Leybold modificado. b) Detalhe do LED com estrela sobre o dissipador de calor.

A estrela de alumínio com o LED foi fixada com parafusos sobre um disco de cobre com cerca de $2 \mathrm{~mm}$ de espessura. Esse disco é importante para ajudar na dissipação de calor e pode ser feito com outros materiais metálicos, como por exemplo, ferro, latão, alumínio, etc. A Fig. 8 ilustra a parte interna da montagem da fonte de luz com o LED de potência e a fonte de corrente constante comercial. 


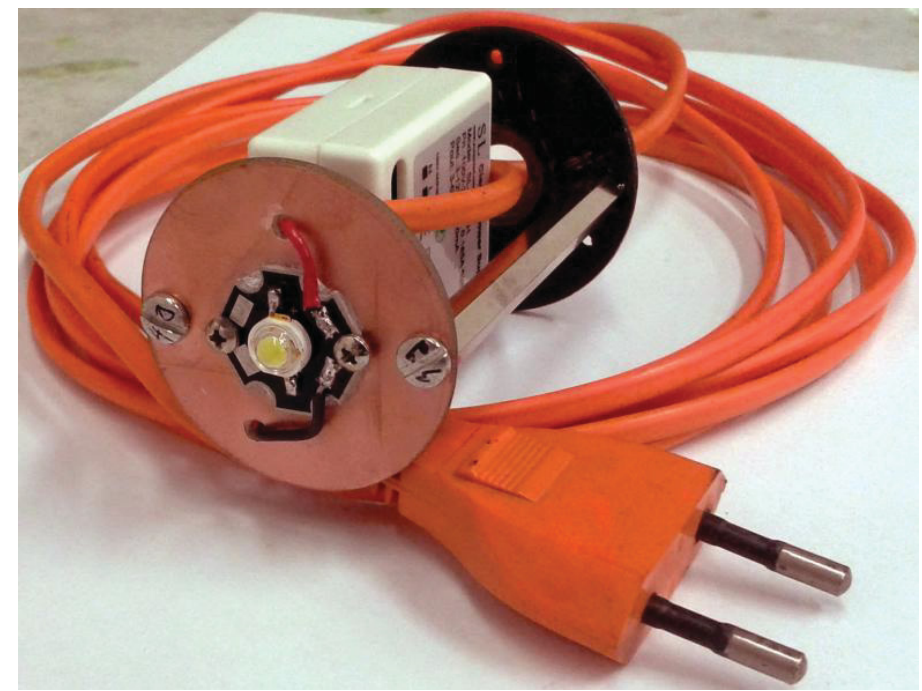

Fig. 8 - Montagem do LED com fonte de corrente constante comercial.

A seguir, as duas montagens são colocadas lado a lado. Uma utilizando a lâmpada incandescente e a outra o LED de potência. Na montagem com a lâmpada incandescente, foi utilizada uma fonte de tensão contínua ajustável ( 0 a $12 \mathrm{~V}_{\mathrm{DC}}$ ), podendo-se assim, variar a intensidade da luz. Já na montagem com o LED de potência, a tensão e a corrente são fixas e, consequentemente, a intensidade da luz é constante. Na Fig. 9, ilustram-se as duas montagens para simples comparação.

\section{Aplicações}

Com a substituição da lâmpada incandescente pelo LED de potência, a fonte de luz mostrou-se de grande utilidade no laboratório de óptica do Instituto de Física da Universidade do Estado do Rio de Janeiro. Agora ela tem sido utilizada em diversos experimentos de óptica, como por exemplo, na verificação da lei de Snell, na observação da reflexão interna total, na verificação da dispersão cromática da luz, na formação de imagens em lentes e espelhos, na determinação da distância focal de lentes e espelhos esféricos, como luz não polarizada na verificação da lei de Malus, na construção de estroboscópios, experimentos com combinação de cores, etc.

Com a adição de uma lente colimadora acoplada ao LED, pode-se diminuir consideravelmente a abertura do feixe luminoso, obtendo-se, assim, um feixe de 
luz com pequena abertura angular, bastante útil em muitos experimentos de óptica. A seguir, são apresentados alguns dos experimentos citados, realizados com LEDs de potência.

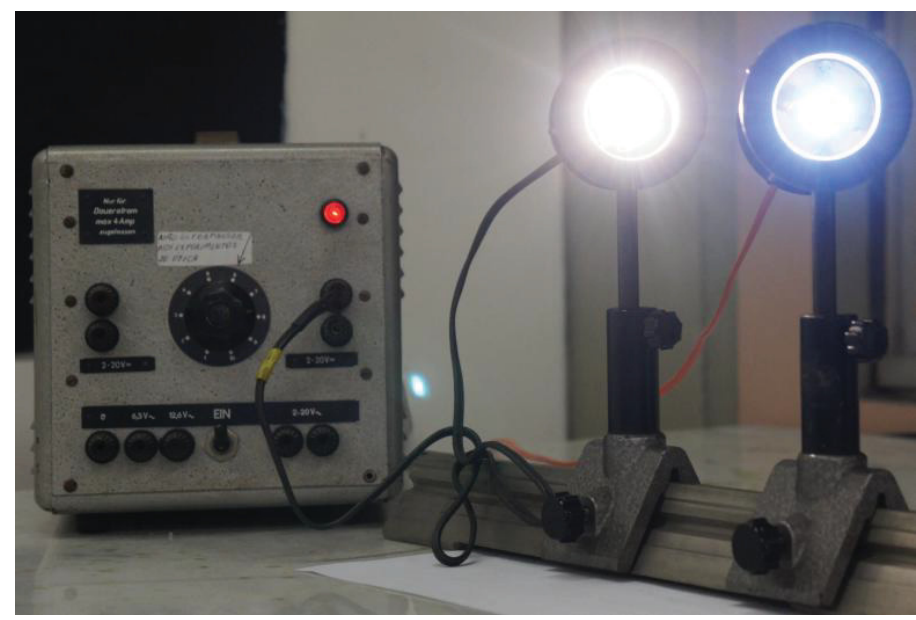

Fig. 9 - Aspecto final da montagem da fonte de luz. Ao lado da fonte de energia está a montagem utilizando lâmpada incandescente e à direita, a montagem com o LED de potência ligado diretamente à rede elétrica.

\section{IV.1 Verificação da lei do inverso do quadrado da irradiância de uma fonte de luz puntiforme}

O objetivo deste experimento é determinar a dependência da intensidade luminosa de uma fonte puntiforme com a distância ao ponto de detecção. Além disso, outras relações poderão ser estudadas, como por exemplo, a aplicação de fotodetectores, o comportamento funcional de uma grandeza física, os limites de validade do experimento e os erros inerentes ao mesmo, etc.

O gráfico da Fig. 10 foi obtido afastando-se o fotodetector da fonte luminosa construída colocada fixa sobre um trilho de metal. A distância do fotodetector à fonte foi variada a partir de $9 \mathrm{~cm}$ (menor distância possível devido à montagem) até $89 \mathrm{~cm}$.

Foi colocado entre a fonte de luz e o fotodetector, uma lente $(f=+50 \mathrm{~cm})$ e um diafragma com abertura muito pequena, ajustados de forma a se obter uma 
fonte pontual. A partir dessa montagem, construiu-se o gráfico da Fig. 10, onde se pode observar que a irradiância de uma fonte pontual é proporcional a $1 / r^{2}$.

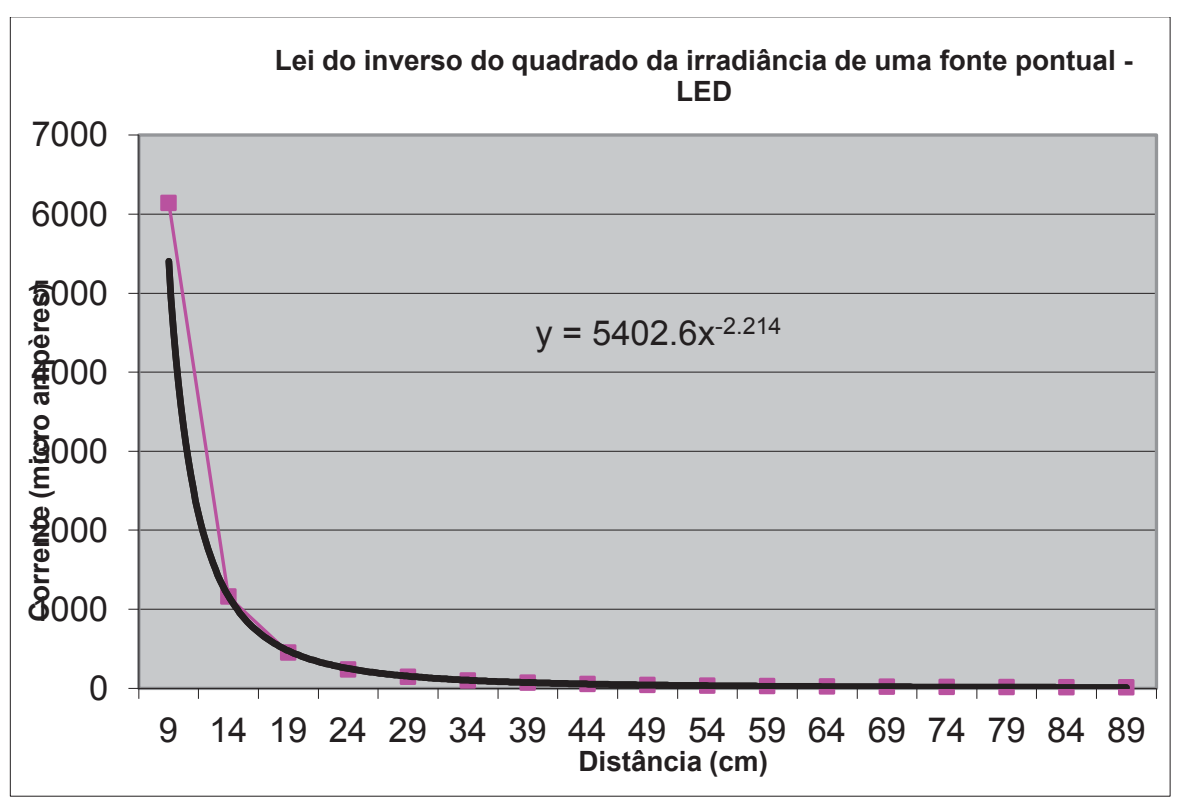

Fig. 10 - Gráfico representativo da lei do inverso do quadrado da irradiância de uma fonte pontual obtido utilizando um LED branco de $3 \mathrm{~W}$ como fonte de luz.

\section{IV.2 Adição de cores}

A cor está relacionada com os diferentes comprimentos de onda do espectro eletromagnético. São percebidas pelas pessoas, em faixa específica (faixa do visível), como uma sensação que nos permite diferenciar os objetos do espaço com maior precisão.

Considerando as cores como luz, a cor branca resulta da sobreposição de todas as cores primárias (vermelho, verde e azul), enquanto o preto é a ausência de luz. Uma luz branca pode ser decomposta em todas as cores (o espectro visível) por meio de um prisma. As cores primárias são cores indecomponíveis e desde as experiências de Le Blond, em 1730, essas cores vêm sendo consideradas primárias. Quando se fala de cor, há que distinguir entre a cor obtida aditivamente (cor luz) ou a cor obtida subtrativamente (cor pigmento) ${ }^{[10]}$. 
A Fig. 11 foi obtida a partir de uma montagem com três LEDs de potência (vermelho, verde e azul), montados nos vértices de um triângulo equilátero de três centímetros de lado, em uma placa de circuito impresso. Na frente dessa montagem foi colocada uma placa opaca com um orifício circular com cerca de três centímetros de diâmetro (o diâmetro não é crítico). A passagem da luz pelo orifício projeta em uma folha de papel branco as cores obtidas pelo processo de adição.

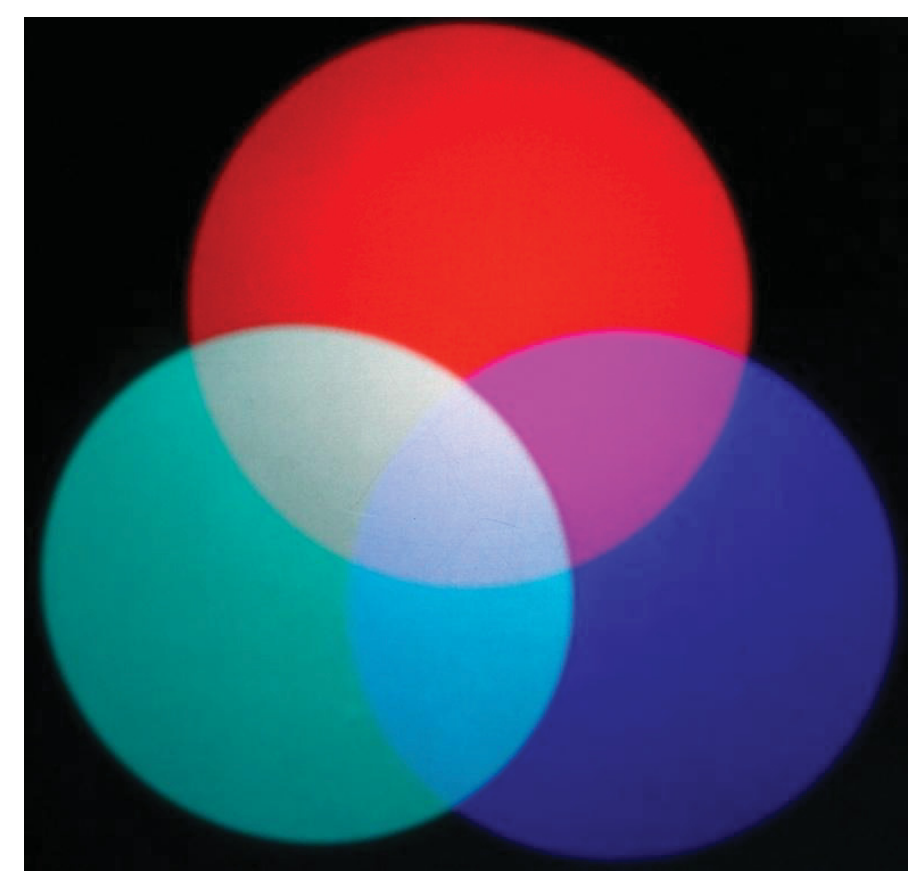

Fig. 11 - Adição de cores obtidas com três LEDs de potência.

\section{IV.3 Refração da luz}

A passagem da luz por uma superfície (ou interface) que separa dois meios diferentes é chamada de refração. A menos que o raio incidente seja perpendicular à interface, a refração muda a direção de propagação da luz. Na A Fig. 12 foi obtida com a ajuda de uma lente colimadora acoplada ao $\operatorname{LED}^{[9]}$. Nela é possível observar que a mudança de direção da luz ocorre apenas na interface; dentro da interface a luz se propaga em linha reta, como no ar. 


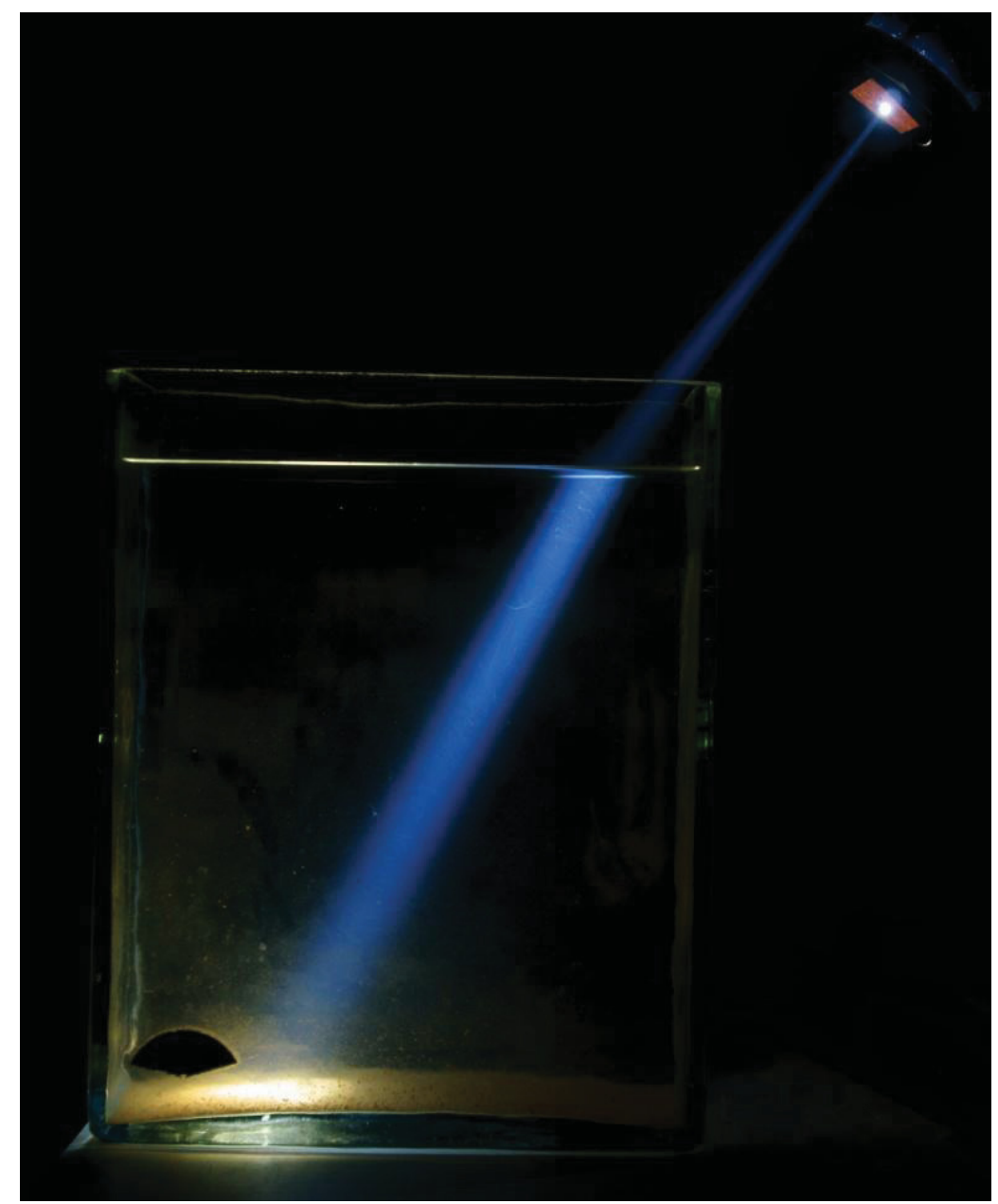

Fig. 12 - Refração da luz obtida com um LED branco frio de potência.

Os feixes luminosos da fotografia estão representados por um raio incidente e um raio refratado (não é possível observar o raio refletido nesta fotografia). A orientação desses raios é medida em relação a uma direção, conhecida como normal, que é perpendicular à interface no ponto em que ocorrem a reflexão e a refração. Assim, com a ajuda de um transferidor, é possível medir o ângulo de incidência e o ângulo de refração. 


\section{IV.4 Estroboscópio}

Um estroboscópio consiste num dispositivo óptico que permite estudar e registrar o movimento contínuo ou periódico de elevada velocidade de um corpo, com o objetivo de fazê-lo parecer estacionário. Obtém-se um conjunto de imagens discretas, mas que são representativas do percurso que o corpo descreve. Esse efeito é conseguido através da alternância entre a iluminação com uma luz intensa e o bloqueio dessa luz por um diafragma. Este dispositivo permite determinar a frequência de rotação de corpos, pois fazendo coincidir a frequência da iluminação com a do movimento, cada feixe de luz ilumina a mesma fase do movimento, resultando numa aparente imobilidade do corpo em rotação. Se a frequência do estroboscópio coincidir com a frequência do processo de medição, o processo parece estar parado. Se não se der a referida coincidência, então o processo avança ou retrocede lentamente a uma frequência maior.

Até recentemente, para se construir um estroboscópio era necessária a utilização de uma lâmpada especial (geralmente uma lâmpada com gás Xenônio) que, além de ser um componente delicado, apresenta alguns inconvenientes, como por exemplo, preço elevado, vida útil relativamente curta e emprego de fonte de alta tensão, que geralmente é produzida por circuitos indutivos, nem sempre fáceis de construir.

Na versão com LED de potência, o aparelho produziu clarões de forte intensidade com frequência estável e ajustável, tal como aquele produzido pela lâmpada Xenônio tradicional.

A Fig. 13 é uma fotografia digital obtida de um pêndulo simples em movimento, iluminado com um estroboscópio construído com um LED de 5 watts. O período de exposição foi de apenas 1,3 segundos.

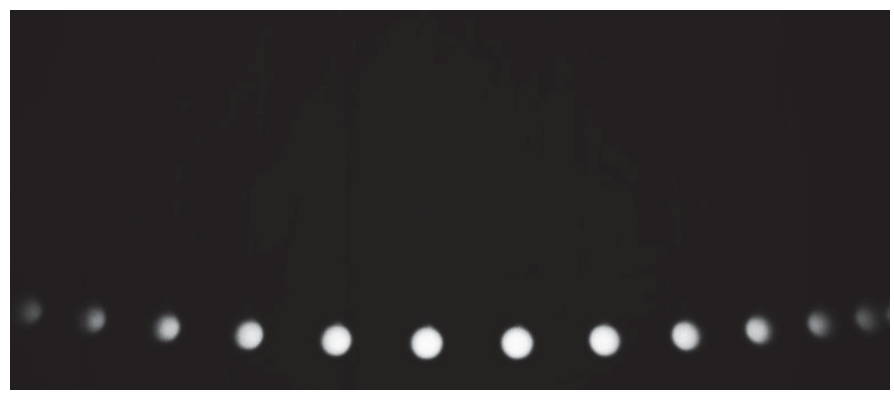

Fig. 13 - Fotografia obtida de um pêndulo simples em movimento iluminado com um estroboscópio de LED. 


\section{Conclusão}

Tradicionalmente as fontes de luz utilizadas nos bancos ópticos dos laboratórios de óptica se utilizam de lâmpadas incandescentes. No entanto, mais recentemente, é comum emprego de lâmpadas fluorescentes compactas nessas montagens. Neste trabalho foi apresentada uma fonte de luz eficiente e de longa vida útil, que faz uso de um LED de potência, em substituição a essas lâmpadas.

Para a realização desse trabalho foi necessário modificar a montagem antiga de uma fonte de luz, de um banco óptico, de forma a substituir a lâmpada incandescente por um LED de potência. Assim, para o funcionamento adequado desse LED e manter a forma compacta do conjunto, foi preciso inserir na montagem uma fonte de alimentação que, além de fornecer a tensão e a corrente correta, apresentasse dimensões reduzidas. Por esse motivo, optamos pela fonte de corrente constante comercial.

A fonte de luz proposta foi comparada com a fonte tradicional e apresentou algumas vantagens, tais como: operação com luz branca de elevada intensidade luminosa, longa vida útil, não possui elementos nocivos ao meio ambiente, funciona com intensidade luminosa constante, pequenas dimensões e peso, imunidade à vibração, operação em temperatura mais baixa, baixo custo relativo, funcionamento com baixa tensão, possibilidade de operar com pilhas, bateria ou diretamente através da rede elétrica, possibilidade de uso de fonte comercial com dimmer, podendo-se assim, variar a intensidade luminosa da fonte variando-se a corrente de operação, etc.

Neste contexto, acreditamos que os resultados experimentais demonstraram a grande utilidade dos LEDs de potência em experimentos de óptica e a sua viabilidade técnica do uso de LEDs de potência em experimentos de óptica.

\section{Referências}

${ }^{\text {[1] }}$ PINTO, R. A. Projeto e Implementação de Lâmpadas para Iluminação de Interiores Empregando Diodos Emissores de Luz - LED. 2008. Dissertação (Mestrado) - Universidade Federal de Santa Maria, RS.

${ }^{[2]}$ JACOB, E. Manual de utilização de LED e fontes de alimentação. Disponível em: <http://pt.scribd.com/doc/126196698/Manual-de-Utilizacao-de-Leds-e-Fontesde-Alimentacao $>$. 
${ }^{[3]}$ MIRANDA, P. H. A.; VARELA, A. T.; SÁ JR., E. M. Análise da eficiência de LEDs de potência em aparelhos odontológicos utilizando o diodo Peltier. In: CONGRESSO DE PESQUISA E INOVAÇÃO DA REDE NORTE E NORDESTE DE EDUCAÇÃO TECNOLÓGICA - CONNEPI, IV, 2009, Belém, PA.

[4] EdiPower II Star Series Datasheet. Edison Opto Corporation. Disponível em: $<$ www.edison-opto.com. 2012>

${ }^{[5]}<$ http://www.opoen.com.br/home/produto/codigo:14875,familia_id:185/ledbranco-frio-3w-emitter $>$

${ }^{[6]}<$ http://www.opoen.com.br/home/categoria/familia pai id:185/leds-de-potencia $>$

${ }^{[7]}$ Driver para LED. Opoen Eletrônica Ltda. Disponível em: $<$ http://www.opoen.com.br>.

${ }^{[8]}<$ http://www.superled.com.br/DriverLED700mA $>$

${ }^{[9]}<\mathrm{http}$ ://www.opoen.com.br/home/categoria/familia_id:174/lentes $>$

${ }^{[10]}<$ http://pt.wikipedia.org/wiki/Cor $>$ 